\title{
ISOMETRIC COMPOSITION OPERATORS ON THE FOCK-SPACES
}

\author{
Anuradha Gupta And Pooja Sharma
}

\begin{abstract}
In this paper a necessary and sufficient condition for a holomorphic self map $\phi$ on $\mathbb{C}^{N}$ to induce an isometric composition operator on the Fock space has been obtained. Some necessary and sufficient conditions for a composition operator $C_{\phi}$ to be a quasi-isometric and $m$-isometric have also been explored.
\end{abstract}

Mathematics subject classification (2010): 47B33, 46B04, 30H20.

Keywords and phrases: Composition operators, isometry, Fock spaces.

\section{REFERENCES}

[1] J. AgLeR AND M. Stankus, m-Isometric transformations of Hilbert space, I, Integral Equations Operator Theory, 21, (1995), 383-429.

[2] R. F. Allen AND F. ColonnA, Isometries and spectra of multiplication operators on the Bloch space, Bull. Aust. Math. Soc., 79, (2009), 147-160.

[3] R. F. Allen And F. Colonna, On isometric composition operators on the Bloch space in $\mathbb{C}^{N}$, J. Math. Anal. Appl., 355, (2009), 675-688.

[4] R. F. Allen, K. C. Heller AND M. A. Pons, Isometric composition operators on the analytic Besov spaces, J. Math. Anal. Appl., 414, no. 1 (2014), 414-423.

[5] B. J. Carswell, B. D. MacCluer and A. Schuster, Composition operator on the Fock space, Acta Sci. Math. (Szeged), 69, (2003), 871-887.

[6] F. Colonna, Characterization of the isometric composition operators on the Bloch space, Bull Aust. Math. Soc., 72, (2005), 283-290.

[7] S. M. GRUdSKY AND N. L. VASILEVSKI, Toeplitz operators on the Fock space: Radial component effects, Integral Equations Opertors Theory, 44, (2002), 10-37.

[8] R. Horn and C. Johnson, Matrix Anslysis, Cambridge University Press, Cambridge, 1990.

[9] S. Janson, J. Pectre And R. Rochberg, Hankel forms and the Fock space, Rev. Math. Iberoamericane, 3, (1987), 61-129.

[10] C. J. Kolas KI, Isometries of weighted Bergman spaces, Can. J. Math., 34, (1982), 910-915.

[11] C. J. Kolas KI, Surjective isometries of weighted Bergman spaces, Proc. Amer. Math. Soc., 105, (1989), 652-657.

[12] J. LAITILA, Isometric composition operators on BMOA, Math. Nachr., 283, (2010), 1646-1653.

[13] G. L. LI AND Z. H. ZHOU, Isometries on product of composition and integral operator on Bloch type spaces, J. Inequal. Appl., 8, (2010).

[14] M. J. MARTIN AND D. VUKOTIC, Isometries of some classical function spaces among the composition operators, Contem. Math., 393, (2006), 133-138.

[15] M. J. MARTIN AND D. VUKOTIC, Isometries of the Dirichlet space among the composition operators, Proc. Amer. Math. Soc., 134, no. 6 (2006), 1701-1705.

[16] M. J. MARTIN AND D. VuKOTIC, Isometries of the Bloch space among the composition operators, Bull. Lond. Math. Soc., 39, (2007), 151-155.

[17] W. NOVINGER AND D. OBERLIN, Linear isometries of some normed spaces of analytic functions, Can. J. Math., 37, (1985), 62-76.

[18] S. M. PATEL, A note on quasi-isometries, Glasnik Mathematicki, 35 (55), no. 2 (2000), 307-312.

[19] K. Stroethoff, Hankel and Toeplitz opertors on the Fock spaces, Michigan Math. J., 39, (1992), $3-16$. 
[20] R. WALLSTEn, The $S^{p}$-criterion for Hankel forms on the Fock spaces $0<p<1$, Math. Scan., 64, (1989), 123-132.

[21] SEI-ICHIRO UEKI, Hilbert-Schmidt weighted composition operator on the Fock space, Int. Journal of Math. Anal., 1, no. 16 (2007), 796-774.

[22] K. ZHU, Analysis on Fock spaces, Graduate Texts in Mathematics 263 (Springer, New York, 2012).

[23] N. ZorboskA, Isometric composition operators on the Bloch-type spaces, C. R. Math. Acad. Sci. Soc. R. Can., 29, no. 3 (2007), 91-96. 